A few years ago, I was favoured by Professor Gibson of Philadelphia with notes of his two interesting cases of Cæsarian operation, which were performed by that distinguished surgeon upon the same woman, and were both equally successful. The first was in March, 1835; the second in November, 1837. It appears, according to Dr. Gibson's account, that these were her third and fourth labours; and that in her two previous labours she had been delivered with great difficulty, after the destruction of the child by cepha. lotomy. Here again the Cæesarian operation was not performed until it was ascertained that delivery by cephalotomy could not be effected with safety to the patient. I do maintain, therefore, (notwithstanding Dr. Lee's condemnation of the Cæsarian operation,) that where the deformity is such as to make it scarcely possible for cephalotomy to be performed with safety to the mother, we are bound to consider the safety of the child, and are perfectly justified in having recourse to the Cæsarian section.

But it is unnecessary to carry the argument farther;-and I will merely add, for the information of Dr. Lee, and others who may feel interested in this matter, that my Cæesarian patient, Sarah Bate, lived five years after the operation, when she died of pulmonary consumption; her husband having died about twelve months previously of the same disease. The child lived ten months, when it was suddenly taken off by a fit of convulsion.

CONTUSED AND LACERATED WOUND OF THE SPHINCTER ANI AND LOWER PART OF THF RECTUM, EXTENDING ALONG THE ANTERIOR AND POSTERIOR PERIN XUM.

Br E. W. TUSON, Ese, F.R.C.S. \&c.

ON the evening of the 26 th of October I was sent for by my friend Mr. Tucker, of Berners-street, to see a case he had been called to. On my arrival at the patient's residence, in Long-acre, upon examination, I found that the external sphincter ani muscle had been torn through; that the rectum kad been lacerated, both at its anterior and posterior boundary, the wound extending to more than an inch towards the os coccygis, being deeper at the fore part of that bone than at other parts of the laceration; anteriorly it extended more than half an inch, but the urethra was quite free from injury; there was prolapsus of the mucous membrane of the rectum, which presented a lobulated appearance. The patient was forty-two years of age, and occasionally of an irregular mode of living. The accident had happened by his falling (while he was getting through a trap-door in a loft) upon the post of French bedstead which had a knob at the upper end, which must have entered the rectum through the sphincter ani; the patient then falling to the ground, the knob of the bedpost lacerated the sphincter and rectum, reflecting a portion of the nates, on the right side, to an extent of some inches laterally. The whole wound presented a very formidable appearance, which the prolapsus ani increased. A question arose-What plan of treatment should be pursued? Should a portion of the wound be brought together by sutures, or not? It was impossible to bring the whole of the wound together without closing the anus. I resolved to return the prolapsus, which was done with some difficulty, but it protruded immediately after I removed my fingers; and as its reduction caused considerable pain, and as it was evident that owing to the division of the sphincter it could not be retained in its natural situation no further attempt was made. I next brought the anterio and posterior parts of the wound together by two sutures, one being placed between the anus and os coccygis, and the other between the anus and scrotum; water dressing was next applied, a graduated compress, and a $\mathbf{T}$ bandage. There had been some loss of blood, which had stopped before we examined the wound. An opiate was given to the patient. On the following morning, we found he had passed a very restless night. He complained of pain in his chest, over the region of the heart, also at the pit of the stomach; the skin was dry tongue furred and clammy; pulse 80 , feeble, intermittent, and compressible. He was allowed a glass of port wine and water, some beef-tea during the day, and was ordered a draught, com posed of solution of acetate of ammonia, half an onnce; decoction of bark, one onnce; compound tincture of cardamoms, one drachm; to be taken every six hours.

On the third day after the accident the wound sloughed, the sutures were torn through, and the whole of the exposed surface presented a very unfavourable appearance. The sloughing portions were dressed with a solution of chloride of cardon, half a drachm to eight ounces of water; warm water dressing applied; a compress and $T$-handage. He was to take mockturtle soup, some game for his dinner, and about five or six glasses of wine in the course of the day. Ordered, decoction of bark, an ounce and a half; tincture of bark, one drachm: aromatic confection, one scruple, every six hours, with a pill. of one grain of opium. The following day the slough evidently extended. The patient had passed a very bad night, was delirious; the hand was unsteady, and he suffered much in his chest. Delirium tremens was added to the sloughing of the wound. Four grains of quinine every four hours; a pill of opium, also every four hours, was taken, and a grain of muriate of morphia at night. The quantity of wine was increased and some bottled stout ordered. This plan produced a change for the better: some sleep at short intervals was procured, and a few days afterwards the sloughing parts began to separate, hea'thy granulations appeared at some places, but the slough towards the anus still remained. The same plan of treatment was followed, excepting the opium being so frequently taken, and a marked improvement was apparent.

Up to the eighth day the bowels had not acted. A pint of gruel, with two ounces of castor oil, was given as an enema, which was retained. On the ninth day, the injection was repeated, but it soon returned unchanged. An aperient draught was ordered to be taken the last thing at night, and the injection on the following morning produced a free evacuation. The prolapsus completely sloughed, and also the whole surface of the wound, at some places to a small extent, at other parts to a greater depth. The wound gradually contracted, and at the end of seven weeks he was quite well. The motions passed freely without pain, and he was able to purstue his usual occupation without any inconvenience.

It was interesting to watch the progress the wound made after the slough had separated, and it was doubtful what the condition of the parts would be when completely healed. The muscular fibres of the sphincter muscle have united; and it was remarkable that Nature restored this muscle with its normal power, particularly after so much of the muscular fibres, both at the anterior and posterior part of the wound, must have been removed. The prolapsus was also cured by the sloughing of the mucous membrane, which removed all appearance of any projection, and when the wound had healed the parts were in a natural condition. The wound was brought together by sutures, for the purpose of preventing the edges becoming everted, also for producing a degree of support ta the prolapsus, so as to prevent a greater portion protruding. Harley-street, January, 1851.

\section{ON THE DRACUNCULUS, OR GUINEA-WORM OF INDIA.}

BY J. BERNCASTLE, M.D., M.R.C.S., \&c., London.

Doring a three months' stay in the Bombay Presidency, I had. frequent opportunities of observing cases of this very remarkable disease. Its most common seat appears to be in the feet and legs, but other parts of the body are not exempt. Some pain is often felt; and a pimple appears, which becomes inflamed, and remains chronic, or terminates as a boil : this first. calls the attention of the patient to the spot, and he seeks for medical aid, when the diagnosis is soon made out by the worm being distinctly traced with the finger in its course underneath the skin, and feeling hard like catgut. An incision is carefully made at the spot where it was first detected, and the worm being seized with the forceps, is drawn out gently, and wound round a quill, care being taken not to break it by any sudden pull, as it would be very painful to fish it out again from the wound into which it might have retracted. If, after having drawn out a certain portion, there is much difficulty in obtaining any more without using undue force, the quill, with the part wound round it, is carefully secured with somage to the patient's leg, and on the next day, $h$ aserergoes another sitting, and so on until the parasite is entirely extirpated : sat cito si sat bene is here the guide. The operation sometimes causes great pain, according to the nervous sensibility of the part. Some persons have more than one worm at the same time in different parts. Both Europeans and natives are subject to the affection: I met many of the former who had suffered from it, but they were residents. I never knew a casual visitor to India to be similarly affected. The origin of the clracunculus is very obscure, and nobody seems to. have any idea of the cause of this parasitical animal locating itself in the human subject. Some have thought that bathing in the tanks might occasion it, but there does not appear sufficient ground to establish that as a cause. The disease is. 